\title{
Teaching Strategies for Incorporating Diversity
}

\section{Andrew Reimann \\ Aoyama Gakuin University \\ Gregory Strong \\ Aoyama Gakuin University \\ Gregory O'Dowd \\ Hamamatsu University School of Medicine}

\section{Jon Dujmovich}

Keio University

\section{Robert McLaughlin}

Tokoha University

\section{Reference Data:}

Reimann, A., Strong, G., O’Dowd, G., Dujmovich, J., \& Mclaughlin, R. (2019). Teaching strategies for incorporating diversity. In P. Clements, A. Krause, \& P. Bennett (Eds.), Diversity and inclusion. Tokyo: JALT.

In this paper, we describe teaching strategies for incorporating diversity into a classroom. One author harnesses active learning to accommodate a range of student abilities and interests in a lecture course on media and mass communications. In this case, the focus is on English as a medium of instruction (EMI), delivering content and using small groups, student reaction papers, project-based learning, and field trips. A second author suggests strategies to promote student reflection on their media consumption, dependency on specific browsers, online retailers, and social networking sites. A third author fosters student awareness of learning strategies and of multiple intelligences through students' cooperatively building vocabulary. Another author promotes student awareness of diversity through eye contact and subsequent discussion. Among other attributes, the Eye-4C-D activity stimulates mindfulness, active listening, and greater awareness of emotional expression. A fifth author uses students' storytelling through visual media, presentations, and film-based narratives for language learning and experiencing diversity.

本論文では、多様性を受容するための様々な教授法について、理論と実践手法を明らかにする。一目の論者は、アクティ ブ・ラーニングを用いて学習者の多様性を包含し、グループワーク、リアクション・ペーパー、プロジェクト、フィールドスタディ を活用し、講義内容の理解を向上させる手法について明らかにする。人目の論者は、メディア利用、ネット検索、ネット通販 やSNSへの依存性について、学習者自身の気づきを促す手法について述べる。三人目の論者は、語彙習得を通して、学習者自 らに学習法と学力の多様性についての認識を向上させる手法を明らかにする。四人目の論者は、Eye-4C-Dアクティビティを通 して、マインドフルネス、積極的な傾聴感情表現への気づきを向上させる教授法について明らかにする。五人目の論者は、視 覚教材やプレゼンテーションを通して、言語学習と多梯性理解の向上を促すことを目的とした学習者の自分語りを用いた教 授法について述べる。

arsen-Freeman (2018) suggested that by taking the minority experience into consideration, we may create better, more inclusive environments for all students and even for teachers as well. She noted, "One gains some humility in the process and with it, learning." Therefore, teacher efforts to accommodate diversity promote professional growth as well. Drawing on complexity theory, Larsen-Freeman compares learning environments to ecological systems, arguing that in such contexts, diversity is a strength not a weakness because systems and organizations that are complex or more diverse tend to be more robust, dynamic, and ultimately stronger. In organizations, this means establishing "a culture of trust," welcoming outsiders, accepting new ideas, and encouraging collaboration (Saynisch, 2010).

The question is how educators promote diversity effectively. The following five authors explore different approaches to raising student awareness of diversity and managing the differences between student values and abilities within the classroom. The authors' 
goals are to develop critical thinking about media, to improve student understanding and participation in a lecture course, to promote student awareness of different learning styles, and to develop empathy and cross-cultural communication skills to make the classroom a more inclusive and supportive learning environment-altogether making our students more successful communicators and global citizens. Their strategies were presented in a forum in promoting and accommodating diversity in the classroom at the JALT2018 Conference.

\section{Accommodating Diverse Student Abilities and Interests in a Lecture Course}

\section{Gregory Strong}

An English lecture course on media and mass communication provides not only an effective use of English as a medium of instruction (EMI), but also an opportunity to deal with diversity because such a course must accommodate a wide variety of student language abilities and interests. Unlike content and language integrated learning (CLIL) that has the twin aims of learning content and language, the focus of an EMI course is primarily academic - on students understanding the content in English (Dearden, 2015).

\section{Context}

Some 60 Japanese juniors and seniors, English majors and predominantly female, take this course each semester. But some terms as many as 125 students join the class.

\section{Diversity}

To accommodate their diverse abilities, interests, and course engagement, the author has tried to adhere to the broad principles of EMI (including visual aids and realia translation of key terms, supplementary readings, and oral repetition) and also that of active learning. As defined by Bonwell and Eison (1991), it encompasses the following general conditions: (a) the students do more than listening, (b) the teacher has less interest in transmitting information and more on developing students' skills, (c) students are engaged in high order thinking (such as making judgements, defending their opinions, and synthesizing information), and (d) greater emphasis is placed on students exploring their attitudes and values.

\section{Method}

Creating student groups at the beginning of the semester aids in active learning by making the students respond to each other, develop answers for questions posed by the lecturer, and comment on each other's assignments. Each student group chooses the name of an international newspaper. The teacher photographs the group and has students identify themselves in their group photo.

Powerful images and video clips for this course, as for many lecture subjects, can be found on Google images and YouTube, and materials can be downloaded from the Internet using apps such as Hyper or Down Load Player or from educator sharing websites such as SlideShare. In terms of content, the spring semester covers early writing systems, the impact of books, and the development of photography; the fall semester describes the evolution of broadcast media and the Internet.

Lecture slides are supplemented by handouts developed around topics in the course such as "manuscripts and illumination" and "newspapers and media literacy." Lecture content in the PowerPoint slides is crafted to pose questions to students: for example, asking them to brainstorm the uses of writing in early civilizations (e.g., accounting, laws, religious service, education), to make predictions, and to summarize material.

Short reaction papers either written in class or as an assignment about contentious issues can engage students in both critical thinking and making judgements. Among numerous media issues are whether the racist language in the classic novel Huckleberry Finn should be replaced by a less offensive word "slave" or whether the "Falling man" image captured by photographer Richard Drew of 9-11 attack in which a man is falling to his death from one of the burning World Trade Center buildings should have been published.

Project-based learning occurs each semester:

1. Early in the spring, students are introduced to the "Communication Pyramid" (McQuaid, 2005, p.18), describing the different levels of the communication process: the intrapersonal level at which an individual keeps a journal or a list; interpersonal communication between two people; communication within a group such as a club; and mass communication, the individual's consumption of mass media such as TV or the Internet. Students reflect on their uses of communication media over a single day and describe this in a paragraph with academic citations for any TV program or Internet content to which they listened.

2. "The Student Photo Project" has student groups choose a theme (e.g., celebrity, the environment, social issues). Each student chooses a photo that fits the group theme, 
downloads it from sites such as Google images, describes the photo and its personal appeal, and provides an APA citation. Each group then "hangs" their photos together in a different area of the classroom, and students in the class wander the room looking at the photos, commenting, and rating them.

3. "The Newspaper Bias Assignment" begins with several lectures showing the bias in different newspaper articles and editorial cartoons covering events such as the containment of radioactivity at the Fukushima nuclear reactors or the dolphin hunt at Taiii, Japan. Students in groups develop their own topics and find articles or cartoons with contrasting bias, then write individual summaries and commentaries on these, again using proper citations. In a subsequent class, these are displayed and viewed in a poster presentation.

4. "The Media Field Trip" occurs near the end of the fall semester when students have learned about national broadcasters such as NHK. Their assignment is to go to the NHK Museum of Broadcasting, document their trip with a selfie, and write a report of their experience.

\section{Conclusion}

Through these means, this lecture course can accommodate a large and diverse student group. By adapting the content for language students, simplifying concepts, providing more visual information, and engaging students in active learning, despite the size of the class, the lecture has become a popular one and students even retake the course. Student evaluations compare it favorably to lectures in which they have a more passive role.

\section{Using Media Literacy to Help Students Understand Diversity}

Andrew Reimann

The need for developing a range of skills for recognizing, understanding, and adapting to diversity has never been greater. Through enhancing student media literacy, teachers can alert students to fake news and alternative facts and teach them how to evaluate sources, detect bias, and better process information. As global efforts and international exchange continue to expand, so too do the requirements for communicating across borders and processing information from multiple sources and perspectives. The following activities and tasks can be used with students at a variety of language abilities.

\section{Context}

These tasks were carried out over several different university classes. Their general nature means that they can be adapted and applied to almost any context. Their personal and introspective nature make them suitable for any level of student abilities. An important element of these tasks is students' sharing and communicating their similarities and differences in media usage as well as their opinions on other matters. This may need some scaffolding to introduce language, keywords, or concepts, depending on the level and the size of class. However, as most students have smartphones and have grown up using them, the concepts will be familiar and generally require minimal explanation.

\section{Issue}

Most students are relatively unaware of the nature of their digital activity. Similarly, they also do not fully realize or understand the impact that their online behavior has on themselves as well as others. It is important to raise students' awareness and media literacy so that they can better understand their actions and attitudes. There are three critical areas that should be addressed: first, the impact of bias on decisions and attitudes; second, the extent and nature of our digital footprint including how we access and consume media; and third, evaluating sources and information to establish validity, reliability, and an overall credibility.

\section{Method}

Media Consumption Survey

In 2018, the World Health Organization (WHO) identified gaming and mobile phone usage as a health issue and addiction, not unlike alcoholism, gambling, or nicotine

(2018). To help students understand their habits, the following list of questions is useful:

- Do you sleep with your phone?

- Do you check your phone for no reason?

- Do you check your phone before sleeping and first thing when you wake up?

- Do you feel uncomfortable when your phone is out of reach?

- Do you use your phone when you are with other people?

- Do you film important events instead of watching them?

- Do you use your phone in the toilet?

Do you feel phantom vibrations? 
Answering "yes" to three or more questions suggests a tendency towards nomophobia or mobile phone addiction (Elmore, 2014, Archer, 2017).

\section{Screen Time Usage}

A further, more concrete task involves directly checking usage activity on the device. Recently, to facilitate moderating behavior and controlling tendencies, several mobile phone manufactures have added features to allow users to monitor their usage and even set limits. On iOS (operating system for Apple products) devices this can be done by accessing settings, battery, and usage. This can give a clear indication of the amount of time or the percentage the device was used for certain activities over a given period.

\section{Digital Diet}

Help students gauge their dependency on the Frightful Five: Google, Apple, Amazon, Microsoft, Facebook (Manjoo, 2017). Which could they easily give up? How would their lives change? Analysis, comparison, and discussion of results is an effective awarenessraising exercise.

\section{Bias Analysis}

Introduce and highlight some of the most common biases affecting student decision making. Simple stereotypes and over generalizations are a good starting point. Students can find examples from social media or advertisements. These can be dissected and analysed to determine the type and impact of bias.

\section{Variable Search Results}

Have students search a typically common or "safe" keyword, such as France or ice cream. After completing the search, they can compare and analyse the differences in their search results. The teacher might lead a discussion on why these differences occur. This task will enable students to realise that they are not just passive consumers of information. Their online behavior is monitored, recorded, and used to influence their attitudes and actions. According to Eric Schmidt, executive chairman of Google, "It will become hard for people to watch or consume something that has not in some sense been tailored to them" (cited in Holman, 2010).

\section{Conclusion}

These tasks encourage a diverse group of students to develop the critical thinking skills necessary to navigate the global networks that have become primary means of communication and interaction. For the international student, global understanding and media literacy are of key importance. Learning about the diversity of perspectives and digital usage is of great value. As the economy of the 21st century is based on connecting or sharing ideas, students also need flexibility and tolerance for differences in others in order to connect easily and efficiently (Potter, 2016). Greater media literacy provides students with the tools and knowledge to protect themselves and helps ensure that the messages, ideas, and content that they share are accurate and inclusive of others.

\section{Developing Vocabulary Through Student Multiple Intelligences \\ Gregory O'Dowd}

Every classroom is diverse as each student is unique. Our challenge as teachers is to recognize this diversity and broaden our repertoire of teaching strategies to meet the needs, strengths, and weaknesses of all students.

\section{Context}

The 1st- and 2nd-year medical students in my context are 18-23 years old, predominantly male. They come from a number of different social backgrounds (some from medical families, some from less affluent families) and various places in Japan (mostly outside Shizuoka prefecture). Many are living away from home for the first time.

\section{Diversity}

Many of these students have a very limited set of learning strategies such as cramming for exams. A common teacher observation is that "they don't know how to study." They are also unfamiliar with active learning (Bonwell \& Eison, 1991), which the university now advocates, and their efforts are geared toward cost-performance or just enough studying to avoid failing. My own perspective is derived from the theory of multiple intelligences (MIs) and associated learning strategies (Gardner, 1983). Gardner originally postulated that effective instruction should acknowledge students' individual learning differences and outlined eight different intelligences upon which are built the broader 
range of human potential: linguistic, bodily/kinesthetic, logical/mathematical, musical, intrapersonal (self-knowledge, intuition), spatial, interpersonal (social), and naturalistic (nature smart).

Gardner hypothesized that each individual is born with the capacity for all eight intelligences, but usually develops one or two of these to a greater degree. Gardner suggested that traditional education too often focuses on the first four and that educators should provide multiple opportunities to develop all intelligences. Since starting to teach this group in 2002, I have engaged in a longitudinal study of the MIs of 1st- and 2nd-year medical students to help them better understand their own abilities and needs and prepare them for their future careers. The first step was to ask students to complete an MI survey to illuminate their preferences and abilities. The survey has a minimum score of 6 and a maximum of 30 for each intelligence. Scores of 6 to 11 indicate that a student experiences a particular deficit, 12 to 18 shows a low preference, from 19 to 20 indicates a medium range, and 24 to 30 is high. A survey of a class in the fall semester of 2018 shows typical results (see Table 1 ).

Table 1. Multiple Intelligences Scores

\begin{tabular}{lccc}
\hline Type & Range & Median - male & Median - female \\
\hline Bodily-kinesthetic & $28-7$ & 16 & 16.0 \\
Interpersonal & $29-10$ & 18 & 19.5 \\
Intrapersonal & $27-12$ & 20 & 19.5 \\
Linguistic & $26-11$ & 19 & 19.0 \\
Logical-math & $28-12$ & 17 & 18.0 \\
Musical & $27-7$ & 19 & 20.0 \\
Naturalistic & $27-12$ & 18 & 17.5 \\
Spatial & $25-12$ & 19 & 18.0 \\
\hline
\end{tabular}

Note. Each intelligence can have a minimum score of 6 and a maximum score of 30 .

As these results show, medical students are generally found in the bottom-medium and high-lower levels of each of these intelligences.

\section{Method}

Vocabulary building is a great necessity in building the students' knowledge base, particularly in the medical field. Therefore, in my classes, there is a cooperative learning approach to develop not only the students' MIs, but also the four skills of reading, writing, listening, and speaking.

First, each student mines the text chapter and makes a list of 10 most important words (in English and Japanese) from both the text and outside sources. Then, the following activities are done:

1. Group members share their lists within their group to examine new vocabulary.

2. The group leader makes a combined list of 20 of the most important vocabulary. Each student writes a few of their list words on the group list and then the group leader checks that there are no repetitions.

3. Each student then writes five flashcards from the list (in English on one side and Japanese on the reverse) and then swaps their set to see the new vocabulary recorded by other students.

4. The group leader now takes all the flashcards and quizzes the group members (i.e., the leader reads the Japanese word and members reply with the appropriate English word). The student who says the correct word first keeps the card and the "top batter" gets points at the end of the activity.

5. Next, the groups exchange card sets and the group top batter now reads the new set of flashcards and quizzes members as before, with points awarded to the new top batter.

6. Students record in their notebook the new words they didn't know.

7. Finally, the teacher takes all the flashcards and lists and checks for key words for inclusion in the next test.

8. After the test, students are allowed to check their wordlists against the test vocabulary in order to determine what vocabulary was important for inclusion in the test.

Following this method, students were able to better develop their ability to select important vocabulary from assigned texts (rather than choose just any words to complete the activity) and actually achieved higher scores in subsequent tests. 


\section{Conclusion}

Through this method, students engaged in active learning, practiced all four skills while building their medical vocabulary, and became more successful at noticing key vocabulary. In the process, students also engaged in developing their Mls through active learning. Further still, one of the more noticeable outcomes was the smiles on the faces of students as they participated in this competitive activity and team-building process. In this way, the diverse classroom can become an effective learning environment for all students in which to experience the multiple perspectives that may contribute to the positive development of the academic, emotional, and social skills needed in our future doctors.

\section{Using the Eye-4C-D Method to Promote Student Awareness of Diversity}

Jon Dujmovich

The Eye-4C-D method is an original communicative tool, created by the author, for fostering intercultural competence amongst a broad spectrum of audiences (Dujmovich, 2019). The eye in the title stands for one minute of silent eye contact, the $4 \mathrm{C}$ stands for the four different turns that partners take in communicating, and the $D$ means discussion. Aimed at improving intercultural communicative skills, this method includes important elements of mindful communication (Ting-Toomey, 2015) such as active listening, control and recognition of emotional expressions, and empathy building as well as communicative strategies and authentic language production. Simple and straightforward, structured yet flexible, student centered, and experiential, the method provides a dynamic tool for use in language learning settings.

\section{Context}

The Eye-4C-D method has been used both in Japan and abroad, with small and large groups, in various educational and corporate training environments. I have used it extensively in Japanese educational contexts such as high schools, vocational and technical colleges, and universities.

\section{Diversity}

A major strength of this method is the applicability to a wide range of audiences, learning situations, and diverse contexts.

\section{Method}

This method is short, usually taking about 15 minutes in total, and can be easily incorporated at any point in a lesson. It functions best when it is utilized multiple times throughout a course. It works very well at the beginning of a lesson to introduce vocabulary and concepts connected to larger topics or themes in the lesson. Following are the steps:

1. The facilitator explains the purpose of the exercise and asks for the group's cooperation. Depending on the students' ages and their level of comfort working with each other, the facilitator assigns partners or has the students choose their own.

2. In pairs, the students make eye contact with each other and maintain the eye contact for 1 minute without breaking it.

3. Following eye contact is a period of one-way communication. Each partner takes a turn speaking and listening for 2 minutes, twice each (total duration 8 minutes). While one partner is speaking, the other is actively listening and will have a chance to provide feedback on what his/her partner said during the discussion portion. Preselected speaking topics are provided by the facilitator just prior to each participant speaking. Topics are usually connected to lesson or training themes.

4. In the final step of the method, the participants relax and discuss their topics for 5 minutes. Participants are encouraged to paraphrase what they heard before giving opinions and to ask questions.

5. There are numerous subtleties and nuanced themes that can be emphasized during this activity such as mindfulness of others, showing emotional restraint, recognition and management of facial expressions, induced and managed stress, and information retention and feedback.

The method is most effectively used in communicative language settings by introducing vocabulary, terms, or phrases related to a lesson plan. For example, in a lesson on past tense verbs, a facilitator might ask participants to talk about yesterday, last week, last year, or childhood in the $4 \mathrm{C}$ section, followed by a discussion of the past.

\section{Conclusion}

The Eye-4C-D method is useful for a diverse range of nonnative language learning settings. First of all, there is the ease and versatility of the method, which requires little preparation and a minimum of class time. Second, learners can become more comfortable making eye contact and this can help them in public speaking, for example, 
by enabling them to scan the audience when presenting. Third, the method creates a means for the facilitator to gauge learner awareness of topics, themes, or language presented to the class prior to the lesson. It encourages participants to improvise and recall vocabulary in order to speak about any given subject. In addition, participants can practice mindfulness and develop skills associated with emotional intelligence in a controlled and safe environment. Furthermore, the practice of active listening encourages students to seek clarification and perhaps even suspend initial judgments of others. With repeated use, the Eye-4C-D method offers a powerful classroom communicative tool that can assist learners in overcoming some frequent intercultura communication stumbling blocks.

\section{Exploring Diversity Through Student Storytelling \\ Robert McLaughlin}

The role of storytelling in daily communication has been acknowledged as having primary importance, both in its frequency and in its role for conveying ideas, thoughts, and emotions and even the very identity of its speakers (Coulson \& Jones, 2009; Lucarevschi, 2016). Proponents of its use in the language classroom also claim effectiveness in raising motivation and interest as well as promoting fluency through interactive communication with a focus on speaking and listening skills (Atta-Alla, 2012, Kim, 2010; Wajnryb, 2003). For Japanese students, often characterized as passive and lacking motivation (Perkins, 2008), the explicit teaching of storytelling is a way to promote active participation in the classroom and help students to focus on grammatical features and vocabulary.

\section{Context}

The classes described here are mandatory oral communication classes and all are within the Faculty of Foreign Language Studies. All students are English language majors and are streamed according to TOEIC scores. Nearly all students measure their proficiency in English by TOEIC tests throughout the 4-year program, and a majority take the EIKEN Test in Practical English Proficiency throughout their studies.

\section{Issue}

These classes lack much diversity as $70 \%$ are female and most students are from the local area. There are no visiting foreign students, and there are very few students with an ethnicity other than Japanese. However, each grade level has one or two returnee students and $25 \%$ of the students will travel outside of Japan to study, mainly in Canada and Australia, at some point during their studies. A few students in each class aim to work as English teachers and will be teaching content to raise cross-cultural awareness. Most of the students are studying English with the goal of working in fields that involve cross-cultural contact such as in the hospitality industry or in international business. For these reasons, students need to be exposed to diversity.

\section{Method}

Visual Media Storytelling

To provide an element of realia and a framework for creating a narrative, the textbook, Amazing!: Canadian Newspaper Stories (Bates, 1991) provides the text for an eight-class storytelling activity. The book furnishes authentic content and reflects diversity through stories of Canada centered on the first nations or aboriginal Inuit culture, stories about recent immigrants to Canada, and heroes such as the disabled athlete Rick Hansen who raised funds for medical research by pushing his wheelchair around the world. Most importantly, scaffolding is provided for students with manga-style storyboards for each newspaper entry. These are structured in a $3 \times 3$ panel style, and are shown as nine separate frames, each corresponding to a paragraph in the actual newspaper article. The news articles themselves have been simplified, much like graded readers, and the originals are provided in the teacher's manual. Moreover, two of the articles have videos available on YouTube, and these can serve as advanced organizers and/or home study materials. Activities include pair work for pretelling the story (using the manga storyboards), retelling the story after a first reading, and continuing the story after the article left off to encourage students to use their creativity and imagination.

Presentation Narrative

As further cross-cultural content and for greater exposure to diversity, this time on a global scale, a student-led poster presentation with a specific narrative is effective. To prepare for this, each student researches the life of a well-known person and finds a story that can be retold during class in small groups. By having the groups change members, the students will tell the story twice. Students are encouraged to ask questions and use speaking strategies for clarification. The instructor prompts students and/or models questions and clarification. In a subsequent class, students present their biographies (poster presentation) on different persons, and each presentation must contain a story 
about the person, using the third person narrative. This poster presentation method allows for communication among small groups and gives the presenter the chance to repeat the story several times.

\section{Film-Based Storytelling}

Film is an effective medium for introducing abstract concepts and narrative styles in a concrete and easily comprehensible format. The 1967 classic about an interracial relationship, Guess Who's Coming to Dinner (Kramer, 1967), is an interesting and easily comprehended film that also introduces issues of diversity. Subtitles can provide some scaffolding and the dialogue is simple enough that key scenes may be retold as a review. Students are asked to speculate on the ending of the film and to recount their favorite parts. A postviewing activity utilizes role-play as students assume the position of one of the four main characters and summarize the story from that character's position. This is conducted in groups of four so that there is no overlay between characters.

\section{Conclusion}

This description is of a multilevel view of approaches to storytelling in oral communication classes. All classes incorporate scaffolding at various levels of structure, as provided by the materials, activities, and instructor. The methods and techniques in these resources allow for repetition practice. This approach gives students the chance to reproduce the theoretical aspects of storytelling that they have studied but also to engage with one another in social ways, promoting the development of their productive and receptive skills. Finally, this further provides an opportunity for students to develop confidence and experience in expressing themselves, a key to discourse and human interaction.

\section{General Conclusion}

These varied approaches to student diversity illustrate how teachers can raise awareness and facilitate learning across differences. Methods discussed include adapting materials to use with the diverse group in a lecture course, implementing self-reflection and discussion for media literacy, reflecting on multiple intelligences among different people, using an experiential technique to explore communication styles, and examining different cultures through narration and storytelling. The five authors have used their experiences in multiple contexts to develop critical thinking and an awareness and appreciation of diversity to improve student understanding and participation both inside and outside the classroom. The techniques described can be adapted to any teaching environment and represent effective strategies for raising students' awareness of diversity, global issues, and communication styles.

\section{Bio Data}

Andrew Reimann is an associate professor and language program coordinator in the English Department at Aoyama Gakuin University, Tokyo. He has a PhD in applied linguistics focusing on intercultural communication and materials design. He teaches classes on comparative culture and intercultural communication. His research interests include raising cultural awareness, communication strategies, and media literacy. Recent publications include Culture Studies Handbook, Culture in Context (Intergraphica Press, 2016) and Humor for Cross Cultural Analysis (TESOL, 2017). <anreimann@yahoo.com>

Gregory Strong is a professor and language program coordinator in the English Department at Aoyama Gakuin University, Tokyo. He has worked in Japan, China, and Canada. Among his publications are graded readers, including Battle for Big Tree Country, language learner literature award winner 2016, and chapters in edited works, including TESOL Voices: Insider Accounts of Classroom Life (2017), Flying Colours: The Toni Onley Story (Harbour Press, 2002), and Adult Language Learners: Context and Innovation (TESOL: 2009).

Gregory O'Dowd is the foreign language instructor at the Hamamatsu University School of Medicine and specializes in speaking and listening skills. His research interests include classroom dynamics, lifelong learning, and problem-based learning. <gvg75@hotmail.com>

Jon Dujmovich has an MA in intercultural relations and currently teaches undergraduate and graduate courses at Keio University. He has over 25 years experience as an intercultural communications trainer and researcher. <jon@intercultural.me>

Robert McLaughlin is a full-time instructor at Tokoha Gakuen Daigaku in Shizuoka and has been teaching English in Japan since 1995. His research interests include learner motivation and cross-cultural learning. <rawbbiemc@yahoo.ca>

\section{References}

Archer, D. (2013, July 25). Smartphone addiction. Psychology Today. Retrieved from https://www. psychologytoday.com/us/blog/reading-between-the-headlines/201307/smartphone-addiction Atta-Alla, M. (2012). Integrating language skills through storytelling. English Language Teaching, 5(12), 1-13. https://doi.org/10.5539/elt.v5n12p1 
Bates, S. (1991). Amazing!: Canadian newspaper stories. Toronto, Canada: Prentice Hall. Retrieved from https://books.google.ca/books?id=Ow46AAAACAA]

Bonwell, C. C., \& Eison, J. A. (1991). Active learning: Creating excitement in the classroom. San Francisco, CA: Jossey-Bass.

Coulson, D., \& Jones, B. (2009) An approach to conversational storytelling in the classroom. In A. M. Stoke (Ed), JALT2008 Conference Proceedings. Tokyo: JALT. Retrieved from http://jaltpublications.org/recentpdf/proceedings/2008/E145.pdf

Dearden, J. (2015). English as a medium of instruction-A growing global phenomenon. British Council. https://doi.org/10.13140/RG.2.2.12079.94888

Dujmovich, J. (2019). Fostering intercultural competency: The eye-4C-D method. In K. Tanaka \& D. Tang (Eds.), Journal of Research and Pedagogy, Global Englishes and Cross Cultural Education, 5(1), 19-28. Otemae University Institute of International Education.

Elmore, T. (2014, Sep. 18). Nomophobia: A rising trend in students. Psychology Today. Retrieved from https://www.psychologytoday.com/us/blog/artificial-maturity/201409/nomophobia-arising-trend-in-students

Gardner, H. (1983). Frames of mind. The theory of multiple intelligences. New York, NY: BasicBooks.

Holman, W. J., Jr. (2010, Aug. 16). Google and the search for the future. Wall Street Journal. Available from https://www.wsj.com/articles/SB10001424052748704901104575423294099527212

Kim, M. (2010). The effects of storytelling on adult English language learners. Linguistic Research, 27(3), 447-473. https://doi.org/10.17250/khisli.27.3.201012.004

Kramer, S. (Producer \& Director). (1967). Guess who's coming to dinner [DVD]. U.S.A.: Columbia Pictures Corporation.

Larsen-Freeman, D. (2018, November). Including all students: A complex systems perspective. Plenary address given at JALT2018: Diversity and Inclusion. Shizuoka, Japan.

Lucarevschi, C. (2016). The role of storytelling in language learning: A literature review. Working Papers of the Linguistics Circle of the University of Victoria, 26(1), 24-44. Retrieved from https://journals.uvic.ca/index.php/WPLC/article/download/15309/6820

Manjoo, F. (2017, May 10). State of the art: Tech's frightful five: They've got us. The New York Times. Retrieved from https://www.nytimes.com/2017/05/10/technology/techs-frightful-fivetheyve-got-us.html

McQuaid, D. (2005). Mass communication theory (5th ed.). London, England: Sage.

Perkins, J. (2008, January). Intrinsic or instrumental: Motivational characteristics of English language learners in Japan. Paper presented at the annual Hawaii International Conference on Education, Honolulu, HI. Retrieved from http://www.eric.ed.gov/PDFS/ ED505563.pdf

Potter, W. J. (2016). Media literacy (8th ed.). Thousand Oaks, CA: Sage.
Saynisch, M. (2010). Beyond frontiers of traditional project management: An approach to evolutionary, self-organizational principles and the complexity theory-Results of the research program. Project Management Journal, 41(2), 21-37. https://doi.org/10.1002/pmj.20159

Ting-Toomey, S. (2015). Mindfulness. In J. Bennett (Ed.), Sage encyclopedia of intercultural competence (pp. 620-626). Los Angeles, CA: Sage.

Wajnryb, R. (2003). Stories: Narrative activities in the language classroom. Cambridge, England: Cambridge University Press.

World Health Organization (2018). 11th revision of the international classification of diseases (ICD11) 2018. Retrieved from https://icd.who.int/ 